\title{
Impact of Amino Acid Addition on Aroma Compounds in Papaya Wine Fermented with Williopsis mrakii
}

\author{
P.-R. Lee ${ }^{1}$, B. Yu², P. Curran ${ }^{2}$, S.-Q. Liu ${ }^{1 *}$ \\ (1) Food Science and Technology Programme, Department of Chemistry, National University of Singapore, 4 Science Drive, \\ Singapore 117543 \\ (2) Firmenich Asia Pte Ltd, Tuas, Singapore 117543
}

Submitted for publication: March 2011

Accepted for publication: June 2011

Key words: fermentation, Williopsis, aroma, papaya wine

\begin{abstract}
The impact of amino acid addition on aroma compound formation in papaya wine fermented with yeast Williopsis saturnus var. mrakii NCYC2251 was studied. Time-course papaya juice fermentations were carried out using $\boldsymbol{W}$. saturnus var. mrakii NCYC2251, with and without the addition of selected amino acids (L-leucine, L-isoleucine, L-valine and L-phenylalanine). Yeast growth and changes in sugars, ${ }^{\circ}$ Brix, organic acids and $\mathrm{pH}$ were similar, regardless of amino acid addition. L-Leucine addition increased the production of isoamyl alcohol and some esters such as isoamyl acetate, isoamyl butyrate and isoamyl propionate, while L-isoleucine addition increased the production of active amyl alcohol and active amyl acetate. L-valine addition slightly increased the production of isobutyl alcohol and isobutyl acetate. L-phenylalanine addition increased the formation of 2-phenylethanol, 2-phenylethyl acetate and 2-phenylethyl butyrate, while decreasing the production of most other esters. This study suggests that papaya juice fermentation with $W$. saturnus var. mrakii NCYC2251 in conjunction with the addition of selected amino acid(s) can be an effective way to modulate the aroma of papaya wine.
\end{abstract}

\section{INTRODUCTION}

In winemaking, an adequate nitrogen level in the grape must is essential for a successful alcoholic fermentation, as assimilable nitrogen has been identified as a key nutrient that regulates yeast growth. The degree of nitrogen availability can affect yeast metabolism, such as volatile compound formation. Several studies have revealed the effects of ammonium addition on the formation of volatile compounds (Hernandez-Orte et al., 2005, 2006). Volatile compounds, including higher alcohols, short to medium-chain fatty acids, ethyl esters and acetate esters, are affected by the type and/or concentration of nitrogen (Bell \& Henschke, 2005). If yeast suffers from nitrogen deficiency during wine fermentation, sluggish or stuck fermentation may occur (Bisson \& Butzke, 2000; Sablayrolles, 2009). In contrast, when supplemented with excessive amounts of ammonium there could be a risk of producing wine with elevated levels of higher alcohols (Beltran et al., 2005), acetic acid (Bely et al., 2003), ethyl acetate (Sablayrolles, 2009) or even ethyl carbamate (Ough et al., 1988).

The papaya (or paw paw, Carica papaya) used in this study is one of the fruits with abundant supply in the tropical region, in contrast to the supply of grapes. However, papayas are relatively low in some amino acids, containing only $9 \mathrm{mg}$ phenylalanine, $16 \mathrm{mg}$ leucine, $8 \mathrm{mg}$ isoleucine and $10 \mathrm{mg}$ valine in every $100 \mathrm{~g}$ of edible portion (USDA, 2009), compared to grapes, with $19 \mathrm{mg}$ phenylalanine, 22 $\mathrm{mg}$ leucine, $11 \mathrm{mg}$ isoleucine and $22 \mathrm{mg}$ valine per $100 \mathrm{~g}$ of grape (Vitis vinifera) (USDA, 2009). Some amino acids, especially the branched-chain amino acids and aromatic amino acids, are important precursors to aroma compounds. Higher alcohols such as isobutyl alcohol, isoamyl alcohol and active amyl alcohol are derived from L-valine, L-leucine and L-isoleucine respectively (Dickinson et al., 1997, 1998, 2000), whereas 2-phenylethanol is formed from L-phenylalanine (Etschmann et al., 2002) by Saccharomyces yeasts and certain non-Saccharomyces yeasts (e.g. Kluyveromyces marxianus). These alcohols can be converted into esters, such as branched-chain or aromatic esters, by both Saccharomyces and non-Saccharomyces yeasts due to the action of alcohol acetyltransferases in the presence of acetyl Co-A. Acetate esters such as isoamyl acetate and 2-phenylethyl acetate are recognised as important flavour compounds in wine, imparting characteristic flavours (Rojas et al., 2001, 2003). Non-Saccharomyces yeasts excrete various enzymes that are responsible for giving the wine its unique characteristics (Pretorius et al., 1999). Glucanase activity has been described in the genus Candida (Strauss et al., 2001), whereas ß-glycosidase activity has been described 
in species of Pichia, Hansenula and Hanseniaspora (Charoenchai et al., 1997). Among the non-Saccharomyces yeasts, Williopsis yeasts are potent producers of esters (Inoue et al., 1997), and Williopsis saturnus in particular has the uppermost ability to convert higher alcohols into the corresponding acetate esters, e.g. isoamyl acetate at a concentration of 12 to $73 \mathrm{mg} / \mathrm{L}$ (Iwase et al., 1995).

Considering the common practice of ammonia addition, increasing recognition of the roles of non-Saccharomyces yeasts in grape and fruit wine fermentation and consumer demand for more unique and stylistic wine, it is of interest to understand the effect of amino acid addition on aroma compound generation by non-Saccharomyces yeasts. The aim of this work was to study the fermentation performance and formation of aroma compounds by $W$. saturnus var. mrakii NCYC2251 in papaya juice, with and without the addition of L-valine, L-phenylalanine, L-leucine and L-isoleucine. The selection of the four amino acids was based on reports that these amino acids have the most influence on aroma compound formation in wine fermentations (Dickinson et al., 1997, 1998, 2000; Hernandez-Orte et al., 2002).

\section{MATERIALS AND METHODS}

\section{Yeast strain and materials}

Freeze-dried Williopsis saturnus var. mrakii NCYC2251 was obtained from the National Collection of Yeast Cultures (Norwich, UK) and propagated following the procedure described by Lee et al. (2010). L-Leucine, L-isoleucine, L-valine, L-phenylalanine, fructose, glucose, acetic acid, citric acid, DL-malic acid and DL-tartaric acid were purchased from Sigma-Aldrich (Oakville, ON, Canada). The pure reference compounds used in the quantitative analysis of the volatile compounds were obtained from Firmenich Asia Ltd (Singapore) and Merck (Darmstadt, Germany). Food-grade DL-malic acid was purchased from Suntop (Singapore). Potato dextrose agar (PDA), bacteriological peptone and malt extract were purchased from Oxoid (Hampshire, England). Potassium metabisulphite was obtained from The Goodlife Homebrew Centre (Norfolk, England).

\section{Fermentation conditions}

The preparation and fermentation of the papaya juice were based on the procedure described by Lee et al. (2010). Papayas of the Sekaki cultivar were washed, juiced and centrifuged $\left(32,140 \times \mathrm{g}\right.$ for $15 \mathrm{~min}$ at $\left.4^{\circ} \mathrm{C}\right)$. The initial Brix was $11.60 \%$ and the $\mathrm{pH}$ was 4.98 . DL-malic acid ( $1 \mathrm{M})$ was added to reduce the $\mathrm{pH}$ value to 3.55 , and the juice was sterilised overnight with $100 \mathrm{ppm}$ of potassium metabisulphite. Laboratory-scale fermentations were carried out in duplicate with conical flasks containing $250 \mathrm{~mL}$ of sterile papaya juice at $20^{\circ} \mathrm{C}$ under static conditions. Each flask was inoculated with $\sim 10^{5} \mathrm{cfu} / \mathrm{mL}$ of $W$. saturnus var. mrakii NCYC 2251 and added with $0.05 \%$ (w/v) of L-leucine, L-isoleucine, L-valine or L-phenylalanine, except for the control. Samples were taken during fermentation (Day 0, 3, 6, 10, 14 and 21).

\section{Analytical methods}

Total soluble solids ( ${ }^{\circ}$ Brix), $\mathrm{pH}$, optical density, sugars, organic acids and aroma compounds were analysed as described elsewhere (Lee et al., 2010), with some modifications. Organic acid separation was carried out on a Supelcogel C-610H column (300 x 7.8 mm, Supelco), using $0.1 \%$ sulphuric acid mobile phase at a flow rate of $0.4 \mathrm{~mL} / \mathrm{min}$ with photodiode array (PDA) detection. The determination of sugar was done on a Pinnacel II amino column (Restek, 150 x $4.6 \mathrm{~mm}$ ) using a mixture of acetonitrile and water $(80: 20)$ mobile phase at a flow rate of $1 \mathrm{~mL} / \mathrm{min}$, and assessed by evaporative light scattering detector (ELSD).

Aroma compounds in the papaya wines were determined by the optimised headspace (HS) solid-phase microextraction (SPME) method, coupled with gas chromatography (GC)mass spectrometer (MS) and flame ionisation detector (FID) (Lee et al., 2010). The fibre used for the absorption of volatiles was a $85 \mu \mathrm{m}$ fused silica fibre coated with Carboxen/ PDMS (Supelco, Sigma-Aldrich, Barcelona, Spain). Papaya wine samples of $5 \mathrm{~mL}$ were extracted by HS-SPME for 50 min at $60^{\circ} \mathrm{C}$ and thermally desorbed into the injector port at $250^{\circ} \mathrm{C}$ for $3 \mathrm{~min}$. Separation was performed with a DB-FFAP column (60 $\mathrm{m} \times 0.25 \mathrm{~mm}$ I.D.) and with the oven temperature programmed to run from $50^{\circ} \mathrm{C}$ (hold time $5 \mathrm{~min}$ ) to $230^{\circ} \mathrm{C}$ at a rate of $5^{\circ} \mathrm{C} / \mathrm{min}$ (final hold for $30 \mathrm{~min}$ ). Helium was the carrier gas at a linear velocity of $1.2 \mathrm{~mL} / \mathrm{min}$. The transfer line temperature was $280^{\circ} \mathrm{C}$. Mass detector conditions were: electron impact (EI) mode at $70 \mathrm{eV}$; source temperature: $230^{\circ} \mathrm{C}$; mass scanning parameters: $3 \mathrm{~min} \rightarrow 22 \mathrm{~min}: \mathrm{m} / \mathrm{z} 25-$ $280(5.36 \mathrm{scan} / \mathrm{s}) ; 22 \mathrm{~min} \rightarrow 71 \mathrm{~min}: \mathrm{m} / \mathrm{z} 25-550(2.78 \mathrm{scan} / \mathrm{s})$ under full-scan acquisition mode. Identification of the eluted compounds was achieved by matching the mass spectrum against NIST 8.0 and Wiley 275 MS libraries, and confirmed by the Linear Retention Index (LRI) value. LRI values on the FFAP column were determined using a series of alkanes $\left(\mathrm{C}_{5}-\mathrm{C}_{40}\right)$ run under identical conditions. Quantification of the selected volatiles was similar to that described in Lee et al. (2010), with additional volatiles included: active amyl alcohol [0.002-0.33 ppm (mg/L)]; isobutyl alcohol $(0.02-$ $3.21 \mathrm{ppm})$; active amyl acetate $(0.002-0.07 \mathrm{ppm})$; isobutyl acetate (0.0001-0.022 ppm); ethyl decanoate (0.001-1 ppm); ethyl dodecanoate (0.001-1 ppm); octanoic acid (0.1$10 \mathrm{ppm})\left(\mathrm{R}^{2}\right.$ values of standard curves were at least 0.98$)$. All samples were analysed in triplicate.

\section{Statistical analysis}

Statistical analysis was performed using one-way analysis of variance (ANOVA) with Microsoft Office Excel, version 2003 (Lee et al., 2010).

\section{RESULTS AND DISCUSSION}

\section{Yeast growth, total soluble solids and pH changes during} papaya juice fermentation

All the fermentations showed similar characteristics in terms of growth kinetics and total soluble solids ( ${ }^{\circ}$ Brix) (Table 1). The $\mathrm{pH}$ did not vary significantly during fermentation, with values maintained at $\mathrm{pH} 3.57$ to 3.68 (Table 1). Both the sugar consumption and the organic acid changes were not affected by the addition of amino acids. The sugar consumption displayed a gradual reduction during fermentation, with preferential utilisation of glucose over fructose (Table 1). This corresponds to the sugar consumption behaviour of $W$. saturnus reported in Lee et al. (2010). 
TABLE 1

Fermentation parameters of papaya wine (day 21) fermented with Williopsis mrakii in the presence of the added amino acids

\begin{tabular}{|c|c|c|c|c|c|c|}
\hline & Day 0 & Control & $\begin{array}{l}0.05 \%(\mathrm{w} / \mathrm{v}) \\
\text { valine added }\end{array}$ & $\begin{array}{c}0.05 \%(\mathrm{w} / \mathrm{v}) \\
\text { phenylalanine } \\
\text { added }\end{array}$ & $\begin{array}{c}0.05 \%(\mathrm{w} / \mathrm{v}) \\
\text { leucine added }\end{array}$ & $\begin{array}{c}0.05 \%(\mathrm{w} / \mathrm{v}) \\
\text { isoleucine added }\end{array}$ \\
\hline $\mathrm{pH}$ & $3.57 \pm 0.01^{\mathrm{a}}$ & $3.67 \pm 0.01^{\mathrm{b}}$ & $3.68 \pm 0.01^{\mathrm{b}}$ & $3.64 \pm 0.01^{\mathrm{b}}$ & $3.67 \pm 0.00^{\mathrm{b}}$ & $3.65 \pm 0.01^{\mathrm{b}}$ \\
\hline${ }^{\circ} \operatorname{Brix}(\%)$ & $11.60 \pm 0.00^{\mathrm{a}}$ & $5.50 \pm 0.08^{\mathrm{bc}}$ & $4.95 \pm 0.11^{\mathrm{c}}$ & $5.36 \pm 0.07^{\mathrm{bc}}$ & $5.32 \pm 0.12^{\mathrm{bc}}$ & $5.98 \pm 0.50^{\mathrm{b}}$ \\
\hline Yeast cell count $\times 10^{6}(\mathrm{cfu} / \mathrm{mL})$ & $0.30 \pm 0.01^{\mathrm{a}}$ & $157 \pm 11.70^{\text {bd }}$ & $136 \pm 6.19^{c}$ & $139 \pm 3.54^{\mathrm{c}}$ & $156 \pm 2.65^{\mathrm{b}}$ & $174 \pm 9.02^{\mathrm{d}}$ \\
\hline \multicolumn{7}{|l|}{ Sugars (g/100 mL) } \\
\hline Fructose & $4.32 \pm 0.01^{\mathrm{a}}$ & $2.16 \pm 0.10^{\mathrm{bc}}$ & $1.59 \pm 0.04^{\mathrm{c}}$ & $2.20 \pm 0.05^{\mathrm{b}}$ & $1.87 \pm 0.01^{\mathrm{bc}}$ & $2.25 \pm 0.14^{\mathrm{b}}$ \\
\hline Glucose & $5.06 \pm 0.01^{\mathrm{a}}$ & $0.69 \pm 0.03^{\mathrm{bc}}$ & $0.55 \pm 0.06^{\mathrm{c}}$ & $0.77 \pm 0.01^{\mathrm{b}}$ & $0.64 \pm 0.05^{\mathrm{bc}}$ & $0.79 \pm 0.01^{\mathrm{b}}$ \\
\hline \multicolumn{7}{|l|}{ Organic acids $(\mathrm{g} / 100 \mathrm{~mL})$} \\
\hline Acetic acid & $0.038 \pm 0.001^{\mathrm{a}}$ & $0.046 \pm 0.001^{\mathrm{b}}$ & $0.049 \pm 0.001^{\mathrm{bc}}$ & $0.047 \pm 0.00^{\mathrm{b}}$ & $0.051 \pm 0.002^{\mathrm{cd}}$ & $0.054 \pm 0.001^{\mathrm{d}}$ \\
\hline Citric acid & $0.271 \pm 0.001^{\mathrm{a}}$ & $0.245 \pm 0.00^{\mathrm{b}}$ & $0.230 \pm 0.00^{\mathrm{c}}$ & $0.231 \pm 0.001^{\mathrm{c}}$ & $0.237 \pm 0.002^{\mathrm{d}}$ & $0.242 \pm 0.003^{\mathrm{b}}$ \\
\hline Malic acid & $0.902 \pm 0.02^{\mathrm{a}}$ & $0.696 \pm 0.01^{\mathrm{b}}$ & $0.648 \pm 0.01^{\mathrm{c}}$ & $0.682 \pm 0.01^{\mathrm{d}}$ & $0.666 \pm 0.02^{\mathrm{e}}$ & $0.687 \pm 0.00^{\mathrm{bd}}$ \\
\hline Tartaric acid & $0.018 \pm 0.001^{\mathrm{a}}$ & $0.008 \pm 0.00^{\mathrm{a}}$ & $0.006 \pm 0.001^{\mathrm{a}}$ & $0.007 \pm 0.001^{\mathrm{a}}$ & $0.007 \pm 0.00^{\mathrm{a}}$ & $0.008 \pm 0.001^{\mathrm{a}}$ \\
\hline
\end{tabular}

a,b,c,d,e Statistical analysis at 95\% confidence level with same letters indicating no significant difference.

The changes in the organic acids were similar in all fermentations, where citric acid remained fairly constant while malic and tartaric acids decreased slightly and acetic acid increased (Table 1). There were statistical differences in the concentrations of organic acids at day 21 among or between the different treatments and the day 0 sample, except for tartaric acid (Table 1). The viable yeast cell populations of all fermentations reached the maximum of approximately $1.36 \times 10^{8}-1.74 \times 10^{8} \mathrm{cfu} / \mathrm{mL}$ at the end of fermentation (day 21 ), from the initial cell population of about $3.0 \times 10^{5} \mathrm{cfu} /$ $\mathrm{mL}$ (Table 1).

\section{Kinetic changes in aroma compounds during papaya juice fermentation}

During papaya juice fermentation, a number of aroma compounds were produced, including fatty acids, alcohols, esters and aldehydes: some were stable, others were metabolised. Aroma compounds that were indigenous to the juice, such as benzyl isothiocyanate, $\beta$-damascenone and some fatty acids such as butyric and hexanoic acids, were utilised (data not shown).

The kinetics of the acetic and hexanoic acids were similar in all the fermentations (data not shown). Hexanoic acid, which was present at relatively high concentrations in the juice, was utilised, while acetic acid increased during fermentation. The addition of amino acids increased the formation of acetic acid in comparison to the control (Table 2). The addition of L-phenylalanine increased the utilisation of hexanoic acid, but reduced the formation of octanoic acid. The addition of leucine and isoleucine produced the highest amount of acetic acid, with relative peak areas (RPA) ranging from 0.49 to $0.56 \%$ that corresponded to the trend in the organic acid results (Table 1). Acetic acid is an undesirable volatile acid in alcoholic beverages and has the capability of imparting a vinegary off-flavour. Great variability in acetic acid production, from about $0.06 \mathrm{~g} / 100 \mathrm{~mL}$ to more than $0.34 \mathrm{~g} / 100 \mathrm{~mL}$ has been observed for non-Saccharomyces yeast (Viana et al., 2008). However, the acetic acid produced in this study was within the acceptable range of 0.02 to
$0.07 \mathrm{~g} / 100 \mathrm{~mL}$ for wine (Lambrechts \& Pretorius, 2000). There were statistical differences in the concentrations of fatty acids between the different amino acids added and the control at day 21 (Table 2).

Ethanol, isobutyl alcohol (2-methyl-1-propanol), active amyl alcohol (2-methyl-1-butanol), isoamyl alcohol (3-methyl-1-butanol) and 2-phenylethanol were the major alcohols produced by yeast strain NCYC2251 during papaya juice fermentation (Fig. 1). The effect of the addition of amino acids on ethanol production varied. Amino acid addition significantly increased their respective higher alcohol production (Fig. 1). Studies have shown that, with the addition of different amino acids, Saccharomyces yeasts and certain non-Saccharomyces yeasts (Kluyveromyces marxianus) are capable of producing the respective higher alcohols through a decarboxylation process of the corresponding $\alpha$-keto acids by Ehrlich's pathway, followed by a reduction to produce the final alcohols (Perez et al., 1992; Dickinson et al., 1997, 1998, 2000; Etschmann et al., 2002). The result of our study are in accordance with these studies, where the fermentation added with L-leucine, L-isoleucine and L-phenylalanine displayed increased production of isoamyl alcohol (19.98 $\mathrm{mg} / \mathrm{L})$, active amyl alcohol $(1.77 \mathrm{mg} / \mathrm{L})$ and 2-phenylethanol $(17.16 \mathrm{mg} / \mathrm{L})$ respectively (Table 3$)$. Those added with either L-leucine, L-isoleucine or L-valine showed markedly increased production of isobutyl alcohol compared to the control (Fig. 1). Based on the concentrations, those added with L-valine produced a relatively high amount of isobutyl alcohol, with $9.17 \mathrm{mg} / \mathrm{L}$ (Table 3). However, slight variation was observed in comparison to the semi-quantified results, which was probably due to the matrix effects from the wine on the HS-SPME (Burman et al., 2005). The final amounts of alcohols at day 21 varied significantly among the different amino acids added and the control (Tables 2 and 3). The results of our study differ from those of Hernandez-Orte et al. (2006) and Garde-Cerdan and Ancin-Azpilicueta (2008), who found that there was no positive correlation between higher alcohol production and the amino acids added, with some, such as isoamyl alcohol, even decreasing. This may 

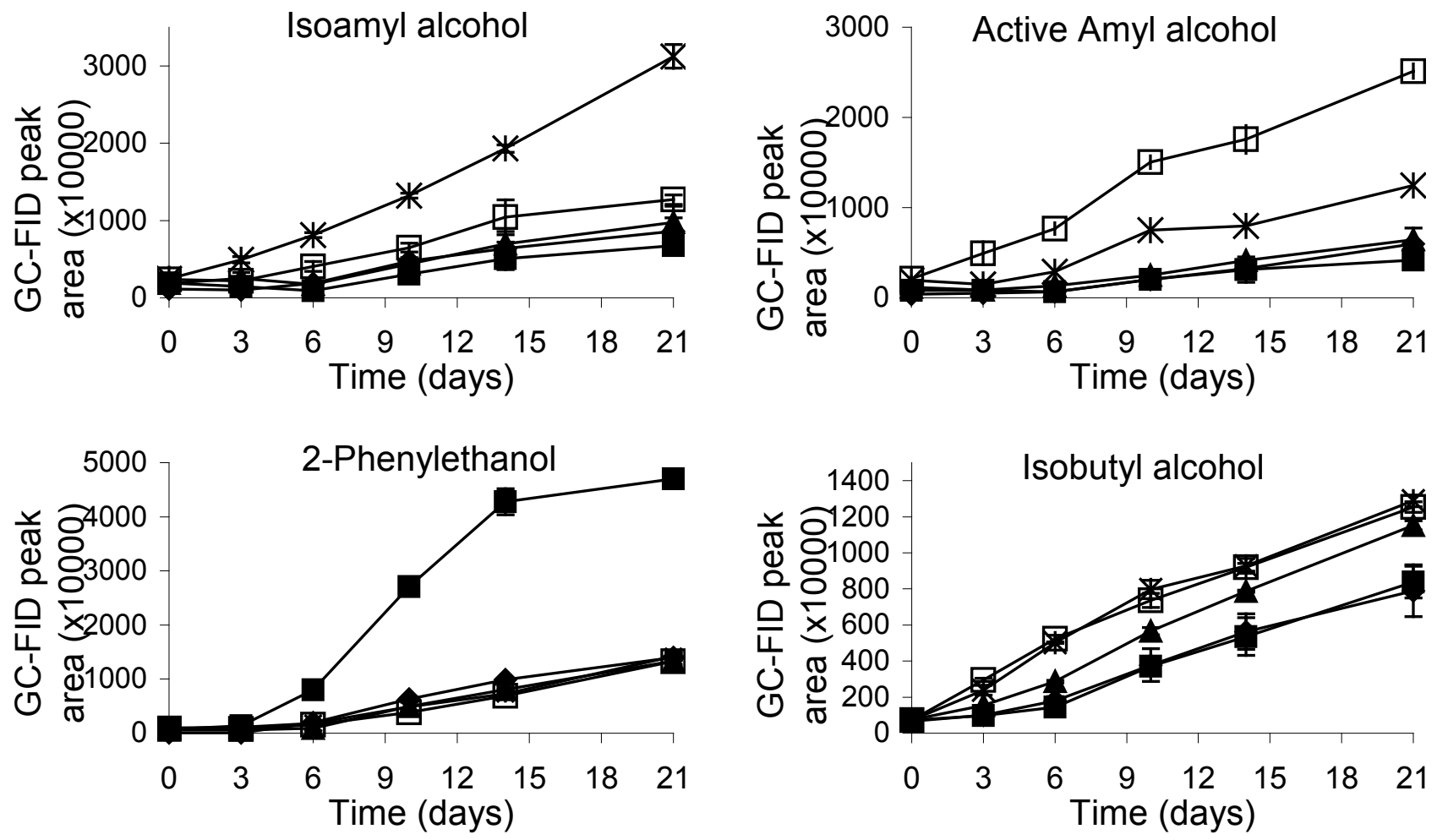

FIGURE 1

Changes in alcohols in papaya wine during fermentation by Williopsis saturnus var. mrakii NCYC2251 with different amino acids added (w/v). Control ( $)$; $0.05 \%$ valine $(\boldsymbol{\Delta}) ; 0.05 \%$ phenylalanine $(\mathbf{\square}) ; 0.05 \%$ leucine $(*) ; 0.05 \%$ isoleucine $(\square)$.
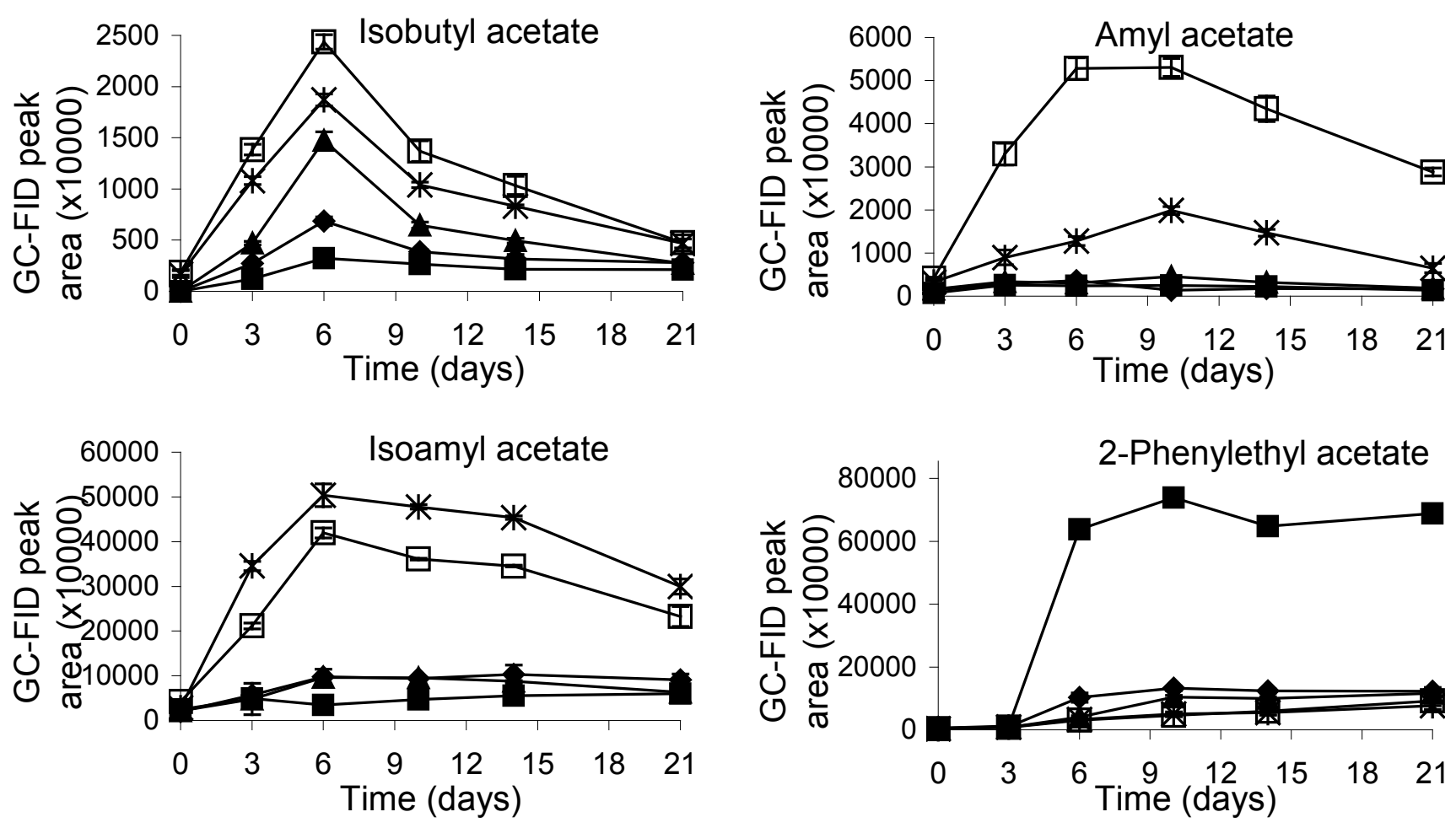

FIGURE 2

Changes in acetate esters in papaya wine during fermentation by Williopsis saturnus var. mrakii NCYC2251 with different amino acids added (w/v). Control ( $)$; $0.05 \%$ valine $(\boldsymbol{\Delta}) ; 0.05 \%$ phenylalanine $(\boldsymbol{\bullet}) ; 0.05 \%$ leucine $\left({ }^{*}\right) ; 0.05 \%$ isoleucine $(\square)$. 


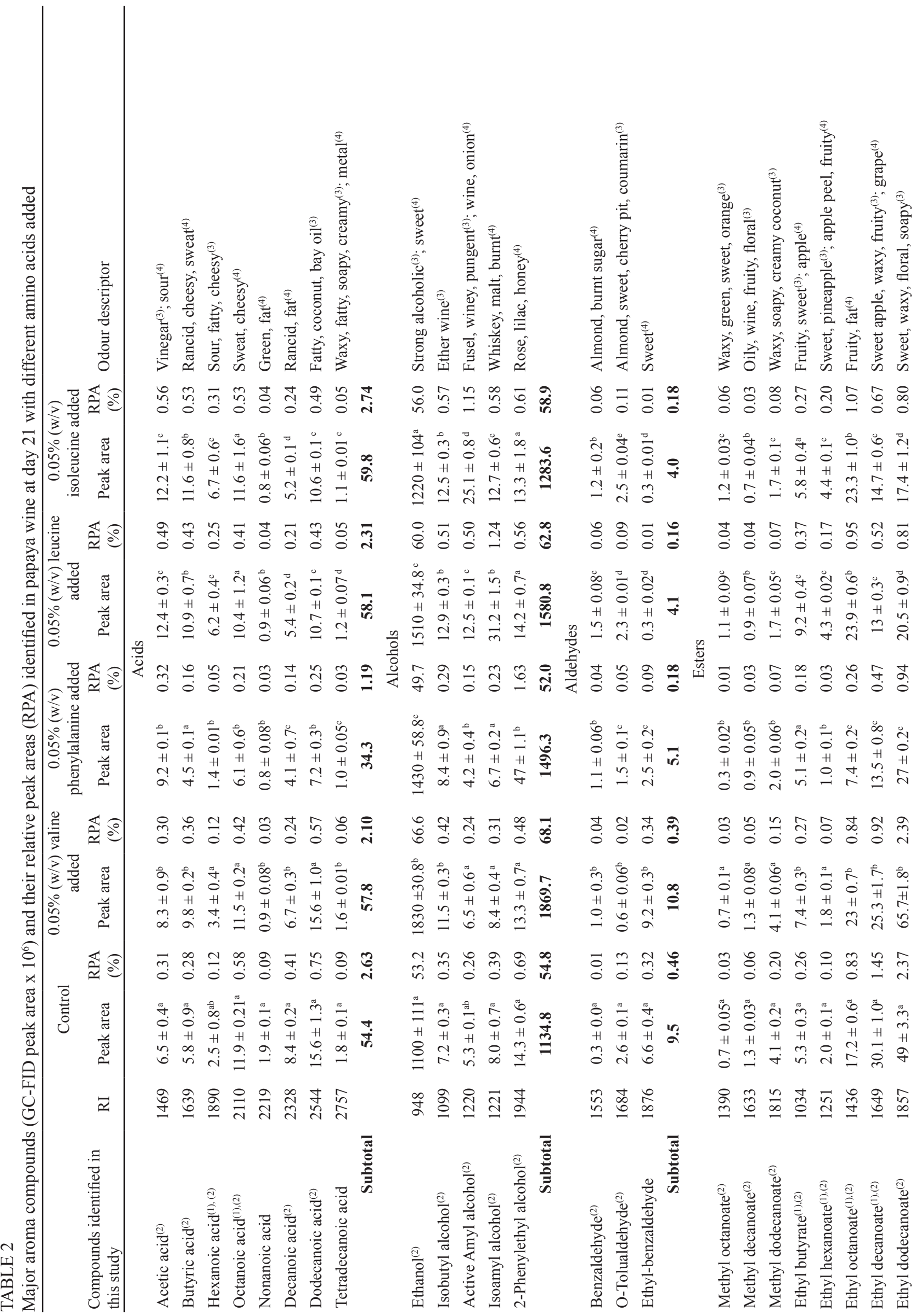




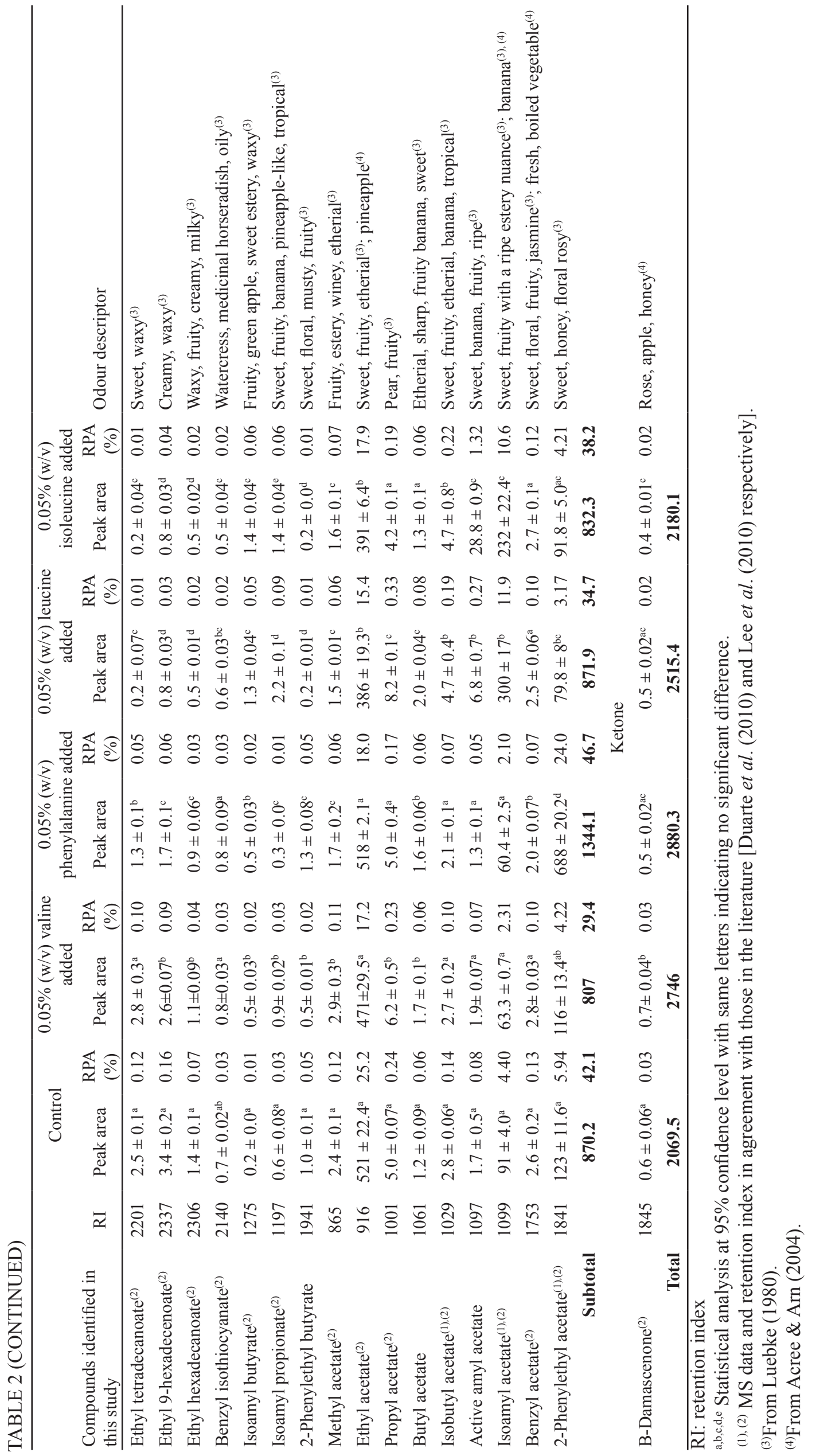



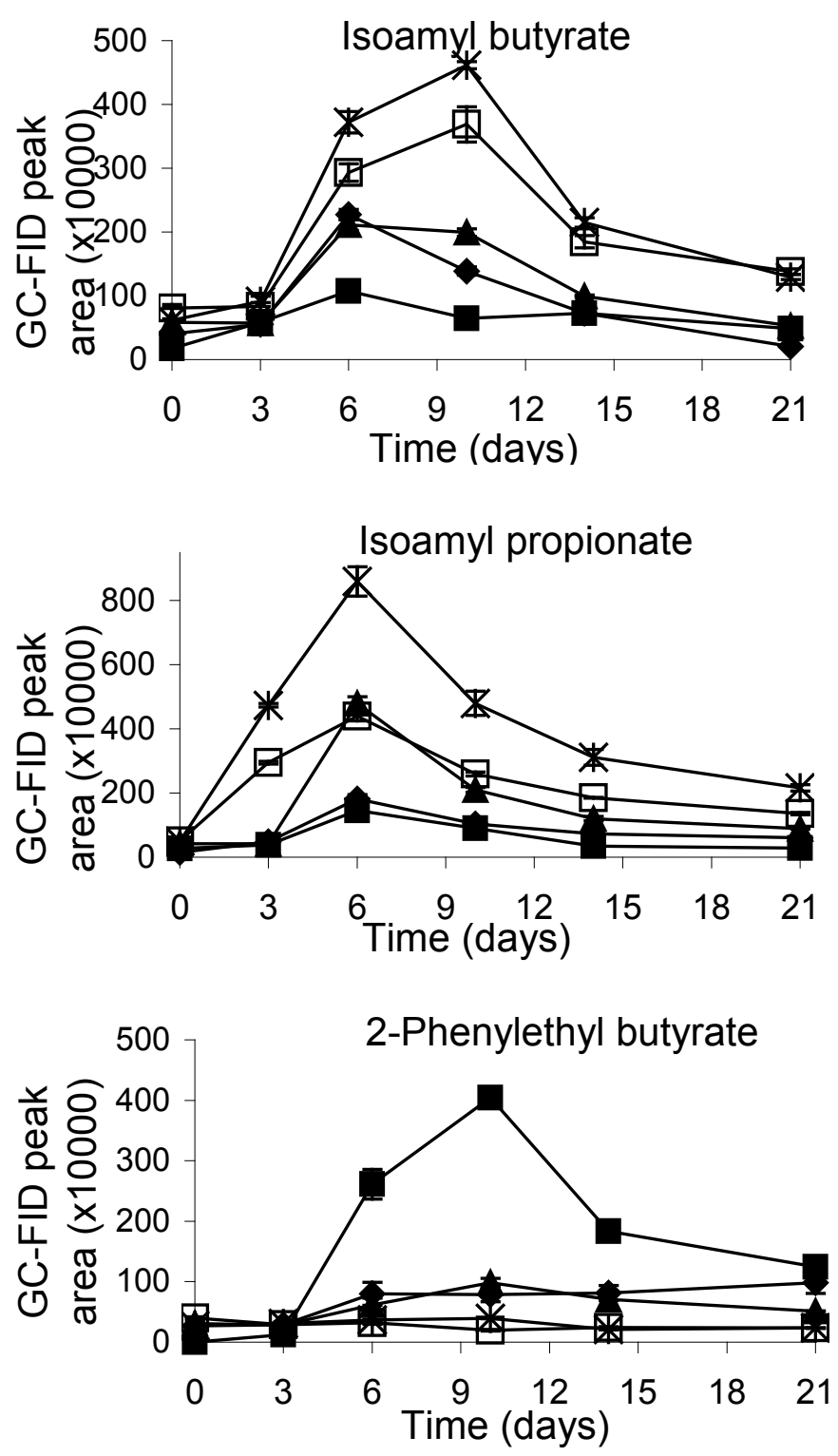

FIGURE 3

Changes in other esters in papaya wine during fermentation by Williopsis saturnus var. mrakii NCYC2251 with different amino acids added (w/v). Control $(\bullet)$; $0.05 \%$ valine $(\boldsymbol{\Delta})$; $0.05 \%$ phenylalanine $(\boldsymbol{\square}) ; 0.05 \%$ leucine $(*)$ ); $0.05 \%$ isoleucine $(\square)$.

be due to the fact that a mixture of amino acids and different yeasts were used in these studies.

Esters were the most abundant aroma compounds produced by yeast strain NCYC2251 during papaya juice fermentation, ranging from 29.4 to $46.7 \%$ (RPA). They included acetate esters, ethyl esters, methyl esters, and other esters (Figs. 2 and 3, Table 2). Acetate esters tended to increase initially and then decline, with the exception of 2-phenylethyl acetate, which increased and remained stable (Fig. 2). Ethyl esters generally increased during fermentation. Among the miscellaneous esters, isoamyl propionate, isoamyl butyrate and 2-phenylethyl butyrate increased initially, followed by a decline (Fig. 3).

The impact of amino acid addition on ester production varied with esters. The addition of L-phenylalanine increased the production of 2-phenylethyl acetate and 2-phenylethyl butyrate, while it reduced the formation of isobutyl acetate, isoamyl acetate and isoamyl butyrate (Figs. 2 and 3). Fermentation with added L-phenylalanine displayed significant production of 2-phenylethyl acetate, at 14.30 $\mathrm{mg} / \mathrm{L}$ (Table 3). The increased production of 2-phenylethyl acetate was likely due to the presence of high amounts of 2-phenylethanol and acetyl-CoA, which provided the necessary precursors for the formation of different acetate esters by the action of alcohol acetyltransferase (AAT) enzymes (Viana et al., 2008). The decreased production of other acetate esters upon the addition of L-phenylalanine (Fig. 2) could be due to competition for and diversion of acetyl-CoA to 2-phenylethyl ester formation, or competition for the uptake of substrates such as amino acids that may serve as aroma precursors.

L-leucine addition enhanced the formation of propyl acetate, isoamyl butyrate and isoamyl propionate and produced the highest amount of isoamyl acetate, at 8.29 
TABLE 3

Concentrations of major aroma compounds $(\mathrm{mg} / \mathrm{L})$ in papaya wine fermented with Williopsis mrakii with different amino acids added at day 21

\begin{tabular}{lccccccc}
\hline \multicolumn{1}{c}{$\begin{array}{c}\text { Compounds } \\
\text { quantified }\end{array}$} & CAS no. ${ }^{(1)}$ & Control & $\begin{array}{c}0.05 \%(\mathrm{w} / \mathrm{v}) \\
\text { valine added }\end{array}$ & $\begin{array}{c}0.05 \%(\mathrm{w} / \mathrm{v}) \\
\text { phenylalanine } \\
\text { added }\end{array}$ & $\begin{array}{c}0.05 \%(\mathrm{w} / \mathrm{v}) \\
\text { leucine added }\end{array}$ & $\begin{array}{c}0.05 \%(\mathrm{w} / \mathrm{v}) \\
\text { isoleucine } \\
\text { added }\end{array}$ & $\begin{array}{c}\text { Odor } \\
\text { threshold } \\
(\mathrm{mg} / \mathrm{L})\end{array}$ \\
\hline Ethanol & $000064-17-5$ & $17122 \pm 546^{\mathrm{ab}}$ & $18712 \pm 63^{\mathrm{a}}$ & $12673 \pm 938^{\mathrm{c}}$ & $16749 \pm 440^{\mathrm{ab}}$ & $16242 \pm 867^{\mathrm{b}}$ & \\
Isoamyl alcohol & $000123-51-3$ & $13.53 \pm 0.91^{\mathrm{ab}}$ & $14.92 \pm 1.46^{\mathrm{ac}}$ & $11.36 \pm 0.93^{\mathrm{b}}$ & $19.98 \pm 1.35^{\mathrm{d}}$ & $17.66 \pm 0.92^{\mathrm{dc}}$ & 30.00 \\
Active amyl alcohol & $000137-32-6$ & $0.69 \pm 0.03^{\mathrm{a}}$ & $0.98 \pm 0.06^{\mathrm{b}}$ & $0.45 \pm 0.05^{\mathrm{c}}$ & $1.10 \pm 0.01^{\mathrm{b}}$ & $1.77 \pm 0.15^{\mathrm{d}}$ & 65.00 \\
Isobutyl alcohol & $000078-83-1$ & $2.26 \pm 0.22^{\mathrm{a}}$ & $9.17 \pm 0.77^{\mathrm{b}}$ & $1.77 \pm 0.18^{\mathrm{a}}$ & $6.00 \pm 0.21^{\mathrm{c}}$ & $6.51 \pm 0.32^{\mathrm{c}}$ & 40.00 \\
2-Phenylethyl alcohol & $000060-12-8$ & $2.29 \pm 0.13^{\mathrm{a}}$ & $2.57 \pm 0.37^{\mathrm{a}}$ & $17.16 \pm 2.48^{\mathrm{b}}$ & $2.24 \pm 0.10^{\mathrm{a}}$ & $1.99 \pm 0.26^{\mathrm{a}}$ & 10.00 \\
Octanoic acid & $000124-07-2$ & $0.37 \pm 0.04^{\mathrm{a}}$ & $0.28 \pm 0.03^{\mathrm{b}}$ & $0.03 \pm 0.00^{\mathrm{c}}$ & $0.28 \pm 0.01^{\mathrm{b}}$ & $0.38 \pm 0.02^{\mathrm{a}}$ & 8.80 \\
Ethyl octanoate & $000106-32-1$ & $0.07 \pm 0.01^{\mathrm{a}}$ & $0.11 \pm 0.01^{\mathrm{b}}$ & $0.04 \pm 0.00^{\mathrm{c}}$ & $0.13 \pm 0.01^{\mathrm{bd}}$ & $0.11 \pm 0.01^{\mathrm{cd}}$ & 0.02 \\
Ethyl decanoate & $000110-38-3$ & $0.29 \pm 0.04^{\mathrm{a}}$ & $0.28 \pm 0.00^{\mathrm{a}}$ & $0.20 \pm 0.02^{\mathrm{b}}$ & $0.23 \pm 0.01^{\mathrm{ab}}$ & $0.25 \pm 0.02^{\mathrm{ab}}$ & 0.20 \\
Ethyl dodecanoate & $000106-33-2$ & $3.97 \pm 0.40^{\mathrm{a}}$ & $4.87 \pm 0.15^{\mathrm{b}}$ & $3.70 \pm 0.10^{\mathrm{a}}$ & $3.55 \pm 0.19^{\mathrm{a}}$ & $3.52 \pm 0.30^{\mathrm{a}}$ & $1.2^{(3)}$ \\
Isoamyl acetate & $000123-92-2$ & $6.48 \pm 0.09^{\mathrm{a}}$ & $6.38 \pm 0.04^{\mathrm{a}}$ & $6.57 \pm 0.18^{\mathrm{a}}$ & $8.29 \pm 0.04^{\mathrm{b}}$ & $7.10 \pm 0.10^{\mathrm{c}}$ & 0.03 \\
Active amyl acetate & $000624-41-9$ & $0.015 \pm 0.00^{\mathrm{a}}$ & $0.015 \pm 0.00^{\mathrm{a}}$ & $0.014 \pm 0.00^{\mathrm{a}}$ & $0.013 \pm 0.00^{\mathrm{a}}$ & $0.06 \pm 0.00^{\mathrm{b}}$ & 0.16 \\
Isobutyl acetate & $000110-19-0$ & $0.008 \pm 0.00^{\mathrm{a}}$ & $0.009 \pm 0.001^{\mathrm{b}}$ & $0.007 \pm 0.001^{\mathrm{ac}}$ & $0.005 \pm 0.00^{\mathrm{c}}$ & $0.007 \pm 0.001^{\mathrm{a}}$ & 1.60 \\
2-Phenylethyl acetate & $000103-45-7$ & $1.76 \pm 0.16^{\mathrm{a}}$ & $1.82 \pm 0.08^{\mathrm{a}}$ & $14.30 \pm 1.64^{\mathrm{b}}$ & $1.37 \pm 0.11^{\mathrm{a}}$ & $1.74 \pm 0.10^{\mathrm{a}}$ & 0.25 \\
\hline
\end{tabular}

$\overline{\mathrm{a}, \mathrm{b}, \mathrm{c}, \mathrm{d}}$ Statistical analysis at $95 \%$ confidence level with same letters indicating no significant difference.

${ }^{(1)}$ CAS number obtained from Wiley MS library.

${ }^{(2)}$ From Bartowsky and Pretorius (2009).

${ }^{(3)}$ Ferreira et al. (2000). The matrix was an $11 \%$ ethanol aqueous solution containing $7 \mathrm{~g} / \mathrm{L}$ of glycerol and $5 \mathrm{~g} / \mathrm{L}$ of tartaric acid, with units adjusted to $\mathrm{mg} / \mathrm{L}$.

$\mathrm{mg} / \mathrm{L}$, while L-isoleucine addition produced the highest amount of active amyl acetate, at $0.06 \mathrm{mg} / \mathrm{L}$ (Figs. 2 and 3, Table 3). Similarly to L-phenylalanine addition, the increased production of isoamyl acetate and active amyl acetate was likely due to the increased amounts of respective higher alcohols, together with the acetyl-CoA produced from the sugars and other substrates. The increased production of other esters with the addition of L-leucine and L-isoleucine could be related to the uptake and metabolism of other substrates, such as the enhanced or inhibited uptake of certain amino acids. Further studies are needed to elucidate this.

The addition of L-valine only slightly increased isobutyl acetate production, by $0.009 \mathrm{mg} / \mathrm{L}$ (Table 3 ). The addition of amino acids did not affect the formation and/or degradation of ethyl acetate and benzyl isothiocyanate, except for those added with L-leucine and L-isoleucine (Table 2). The formation of aroma-active ethyl octanoate was increased with the addition of L-leucine, L-isoleucine and L-valine, while the addition of L-phenylalanine reduced the production of most ethyl esters (Tables 2 and 3). The reduction in the ethyl esters with the addition of L-phenylalanine could be related to the reduced de novo biosynthesis of fatty acyl Co-A associated with fatty acid and/or sugar metabolism. The effect of L-isoleucine and L-valine additions on the production of other ethyl esters varied (Tables 2 and 3 ). The final concentrations of esters were dependent on the stability and determined any significant differences at the statistical level, which varied among the different treatments (Table 2).

\section{Comparison of quantified and semi-quantified major volatiles}

The quantified and semi-quantified volatiles showed generally similar trends (Tables 2 and 3). However, discrepancies were observed between the semi-quantitative and the quantified results for some volatiles, such as ethanol, isobutyl alcohol and isobutyl acetate. This may be attributed to the deterioration of the mixed coating on the fibre upon the extraction of wine samples (Bianco et al., 2009) and possibly thermal deterioration of the fibre with numerous injections. Nevertheless, linear calibration curves obtained in this study had $\mathrm{R}^{2}$ values of at least 0.98 (data not shown), and the relative standard derivation of the results in Table 3 was less than $14 \%$, indicating moderately good repeatability under the analytical conditions used. In general, HS-SPME is used mainly as a qualitative or semi-quantitative method for the analysis of wine aroma compound evolution (Tao et al., 2008). Moreover, Baptista et al. (1998) stated that SPME can also be used as a quantitative method for the accurate and precise analysis of volatiles, as long as consistent and optimised sampling conditions are utilised.

\section{CONCLUSION}

In this study, fermentation performance and the formation/ utilisation of aroma compounds during papaya juice fermentation by $W$. saturnus var. mrakii NCYC2251 were assessed, together with the effects of the addition of amino acids, namely L-leucine, L-isoleucine, L-valine and L-phenylalanine. Overall, W. mrakii showed a capability to produce papaya wine with a wider range of aroma compounds with the addition of a specific amino acid. Papaya juice fermentation with $W$. mrakii, together with adding a specific 
amino acid, can be a valuable tool to modulate the aroma of papaya wine.

\section{LITERATURE CITED}

Acree, T. \& Arn, H., 2004. Flavornet [Online]. Available: http://www. flavornet.org/flavornet.html (Accessed 25 May 2010).

Baptista, J.A.B., da P Tavares, J.F. \& Carvalho, R.C.B., 1998. Comparison of catechins and aromas among different green teas using HPLC/SPMEGC. Food Res. Int. 31, 729-736.

Bartowsky, E.J. \& Pretorius, I.S., 2009. Microbial formation and modification of flavour and off-flavour. In: Konig, H., Unden, G. \& Frohlich, J. (eds.). Biology of microorganisms on grapes, in must and in wine. Springer, New York. pp. 215-217.

Bell, S.J. \& Henschke, P.A., 2005. Implications of nitrogen nutrition for grapes, fermentation and wine. Aust. J. Grape Wine Res. 11, 242-295.

Beltran, G., Esteve Zarzoso, B., Rozes, N., Mas, A. \& Guillamon, J.M. 2005. Influence of the timing of nitrogen additions during synthetic grape must fermentations on fermentations kinetics and nitrogen consumption. $\mathrm{J}$ Agric. Food Chem. 53, 996-1002.

Bely, M., Rinaldi, A. \& Dubourdieu, D., 2003. Influence of assimilable nitrogen on volatile acidity production by Saccharomyces cerevisiae during high sugar fermentation. J. Biosci. Bioeng. 96, 507-512.

Bianco, G., Novario, G. \& Zianni, R., 2009. Comparison of two SPME fibers for the extraction of some off-flavor cork-taint compounds in bottled wines investigated by GC-HRMS. Anal. Bioanal. Chem. 393, 2019-2027.

Bisson, L.F. \& Butzke, C.E., 2000. Diagnosis and rectification of stuck and sluggish fermentation. Am. J. Enol. Vitic. 51, 168-177.

Burman, L., Albertsson, A.C. \& Hoglund, A., 2005. Solid-phase microextraction for qualitative and quantitative determination of migrated degradation products of antioxidants in an organic aqueous solution. J. Chromatogr. A 1080, 107-116.

Charoenchai, C., Fleet, G., Henschke, P. \& Todd, B., 1997. Screening of non-Saccharomyces wine yeasts for the presence of extracellular hydrolytic enzymes. Aust. J. Grape Wine Res. 3, 2-8

Dickinson, J.R., Lanterman, M.M., Danner, D.J., Pearson, B.M., Sanz, P., Harrison, S.J. \& Hewlins, M.J.E., 1997. A ${ }^{13} \mathrm{C}$ nuclear magnetic resonance investigation of the metabolism of leucine to isoamyl alcohol in Saccharomyces cerevisiae. J. Biol. Chem. 272, 26871-26878.

Dickinson, J.R., Harrison, S.J. \& Michael, J.E., 1998. An investigation of the metabolism of valine to isobutyl alcohol in Saccharomyces cerevisiae. J. Biol. Chem. 273, 25751-25756.

Dickinson, J.R., Harrison, S.J., Dickinson, J.A. \& Hewlins, M.J.E., 2000 An investigation of the metabolism of isoleucine to active amyl alcohol in Saccharomyces cerevisiae. J. Biol. Chem. 275, 10937-10942.

Duarte, W.F., Dias, D.R., Oliveira, J.M., Vilanova, M., Teixeira, J.A., Silva J.B.A. \& Schwan, R.F., 2010. Raspberry (Rubus idaeus L.) wine: yeast selection, sensory evaluation and instrumental analysis of volatile and other compounds. Food Res. Int. 43, 2303-2314.

Etschmann, M., Bluemke, W., Sell, D. \& Schrader, J., 2002. Biotechnological production of 2-phenylethanol. Appl. Microbiol. Biotechnol. 59, 1-8.

Ferreira, V., Lopez, R. \& Cacho, J.F., 2000. Quantitative determination of the odorants of young red wines from different grape varieties. J. Sci. Food Agric. 80, 1659-1667.

Garde-Cerdan, T. \& Ancin-Azpilicueta, C., 2008. Effect of the addition of different quantities of amino acids to nitrogen-deficient must on the formation of esters, alcohols, and acids during wine alcoholic fermentation. LWT Food Sci. Technol. 41, 501-510.
Hernandez-Orte, P., Cacho, J. \& Ferreira, V., 2002. Relationship between varietal amino acid profile of grapes and wine aromatic composition. Experiments with model solutions and chemometric study. J. Agric. Food Chem. 50, 2891-2899.

Hernandez-Orte, P., Ibarz, M.J., Cacho, J. \& Ferreira, V., 2005. Effect of the addition of ammonium and amino acids to musts of Airen variety on aromatic composition and sensory properties of the obtained wine. Food Chem. 89, 163-174.

Hernandez-Orte, P., Ibarz, M.J., Cacho, J. \& Ferreira, V., 2006. Addition of amino acids to grape juice of the Merlot variety: effect on amino acid uptake and aroma generation during alcoholic fermentation. Food Chem. 98, 300-310.

Inoue, Y., Trevanichi, S., Fukuda, K., Izawa, S., Wakai, Y. \& Kimura, A., 1997. Roles of esterase and alcohol acetyltransferase on production of isoamyl acetate in Hansenula mrakii. J. Agric. Food Chem. 45, 644-649.

Iwase, T., Morikawa, T., Fukuda, H., Sasaki, K. \& Yoshitake, M., 1995. Production of fruity odor by genus Williopsis. J. Brew. Soc. Japan 90, 394 396.

Lambrechts, M.G. \& Pretorius, I.S., 2000. Yeasts and its importance to wine aroma - a review. S. Afr. J. Enol. Vitic. 21, 97-129.

Lee, P.R., Ong, Y.L., Yu, B., Curran, P. \& Liu, S.Q., 2010. Evolution of volatile compounds in papaya wine fermented with three Williopsis saturnus yeasts. Int. J. Food Sci. Tech. 45, 2032-2041.

Luebke, W., 1980. The good scents company [Online]. Available: http:// www.thegoodscentscompany.com/index.html (Accessed 25 May 2010).

Ough, C.S., Crowell, E.A. \& Mooney, L.A., 1988. Formation of ethyl carbamate precursors during grape juice (Chardonnay) fermentation. I. Addition of amino acids, urea and ammonium: effects of fortification of intracellular and extracellular precursors. Am. J. Enol. Vitic. 39, 243-249.

Perez, A.G., Rios, J.J., Sanz, C. \& Olias, J.M., 1992. Aroma components and free amino acids in strawberry variety Chandler during ripening. J. Agric. Food Chem. 40, 2232-2235.

Pretorius, I., Van der Westhuizen, T. \& Augustyn, O., 1999. Yeast biodiversity in vineyard and wineries and its importance to the South African wine industry: a review. S. Afr. J. Enol. Vitic. 20, 61-74.

Rojas, V., Gil, J.V., Pinaga, F. \& Manzanares, P., 2001. Studies on acetate ester production by non-Saccharomyces wine yeasts. Int. J. Food Microbiol. 70, 283-289

Rojas, V., Gil, J.V., Pinaga, F. \& Manzanares, P., 2003. Acetate ester formation in wine by mixed cultures in laboratory fermentations. Int. J. Food Microbiol. 86, 181-188.

Sablayrolles, J.M., 2009. Control of alcoholic fermentation in winemaking: current situation and prospect. Food Res. Int. 42, 418-424.

Strauss, M., Jolly, N., Lambrechts, M. \& Van Rensburg, P., 2001. Screening for the production of extracellular hydrolytic enzymes by nonSaccharomyces wine yeasts. J. Appl. Microbiol. 91, 182-190.

Tao, Y.S., Li, H., Wang, H. \& Zhang, L., 2008. Volatile compounds of young Cabernet Sauvignon red wine from Changli County (China). J. Food Compos. Anal. 21, 689-694

USDA (The United States Department of Agriculture), 2009. USDA National Nutrient Database for Standard Reference, Release 22 [Online]. Agricultural Research Service, Nutrient Data Laboratory Home Page. Available at: http://www.ars.usda.gov/ba/bhnrc/ndl (Accessed 25 May 2010).

Viana, F., Gil, G.V., Genoves, S., Valles, S. \& Manzanares, P., 2008. Rational selection of non-Saccharomyces wine yeasts for mixed starters based on ester formation and enological traits. Food Microbiol. 25, 778-785. 